\title{
Creation of Breaches, with the Help of Explosives, in Metal Structures under Water and on the Ground Surface
}

\author{
Simona RUS ${ }^{1 *}$, Edith-Hilde KAITER ${ }^{2}$, Bogdan IFTIMIE $^{3}$, Cristian MUNTEANU $^{1}$, \\ Andrei BURSUC ${ }^{1}$, Octavian-Gabriel CHIRIAC ${ }^{1}$ and Livia NICA RUS ${ }^{4}$ \\ ${ }^{1}$ Diving Centre, Blvd.1 Mai, no. 19, 900123, Constanta, Romania \\ ${ }^{2}$ Naval Academy "Mircea cel Bătrân", St Fulgerului 1, 900218, Constanta Romania. \\ ${ }^{3}$ Special Pyrotechnic Service of the General Directorate for Preventing and Combating Terrorism, 287 Blvd. Theodor \\ Pallady, 032271, Bucharest, Romania \\ 4 "Ion Mincu” University of Architecture and Urban Planning, Bucharest, Romania, \\ *Email: simona_elena_rus@yahoo.com
}

\begin{abstract}
The present research-development (CD) paper is a multidisciplinary study requested by the divers belonging to the Diving Center. This study was initiated out of the need to make, with the help of the smallest possible quantities of explosives of very good quality, cutting/sectioning of bars, chains, metal pipes, etc. and breaches of certain shapes and sizes, to enter, as soon as possible, closed enclosures under water (shipwrecks, planes, etc.) in order to recover documents, objects, and so on.
\end{abstract}

\section{INTRODUCTION}

Initially, it was considered that in Romania there were several people who had done doctoral scientific studies over time on some aspects of creating breaches in easy obstacles - but these studies were only for the terrestrial environment. By means of inter-institutional collaboration protocols, on the line of $\mathrm{CD}$, using their experience, the equipment they had at hand and together with civilian and military specialists in the hyperbaric field (engineers, technicians and deep-sea divers, on board, battle and river) from the Diving Center and diving ship divisions, theoretical and practical workshops were initiated and held.

The intense debated topic was: the effect of explosions on metallic and calcareous structures initially in the terrestrial environment and then in the underwater environment. With the help of this "brain storm", several solutions were sought and found in the underwater environment for breaches (holes / spaces through which entrance in underwater enclosures was possible) for the recovery of relics, documents, corpses, etc. In this way, by collaborating on multiple levels and combining the experience of specialists (from prestigious units nationwide) to obtain the desired effects, by professional divers, for their underwater and terrestrial interventions, using as small quantities of 
explosives as possible, so that the environment is as little affected as possible and the tasks entrusted are carried out.

Finally, a product designer was used to obtain optimal shapes and weights for various special explosive devices that could be quickly made, as needed, to 3D printers, which could be easily attached to the specific suits of each group of divers and which does not affect the buoyancy of the diver as a worker in the underwater environment.

The use of explosives for the purpose of making breaches in light obstacles requires knowledge of the mode of action of the explosion on the materials from which they are made.

Starting from the vast experience and expertise gained through practical works and theoretical studies of those who formed the work teams (engineers, divers, pyrotechnicians, breakers, etc.) and through a careful analysis of all theoretical and practical data, the trend was, even from the very beginning, that the most systems of creating breaches in light obstacles, from the arrangement of explosive charges in contact with the obstacle to be cut or perforated. This requires, first of all, the study of the detonation of the explosive substances used and then the study of the methods for determining the detonation parameters.

It should also be noted that some loads also used inert materials (such as water, wood, neoprene, expanded / extruded polystyrene or rubber of appreciable thickness $20 \div 30 \mathrm{~mm}$ ) in order to increase the action of the explosion on the surface of the obstacle. In the terrestrial environment with the purpose of mitigating the effects of the explosion in the directions of the disposition of the intervention personnel and in immersion such materials were used to direct the jet in this almost incompressible environment towards the surface / obstacle that had to be cut.

The main effects of the explosive detonation process are: the generation of shock waves, the propulsion of shrapnel / fragmentation products and the underwater or incendiary earthquake effect. Under these conditions, a study of how to generate shock waves and the propulsion of fragments when detonating explosives is also necessary. The energy resulting from the detonation of explosives is transferred to the material from which the obstacle is made depending on the acoustic impedances of the explosive and the material, this being another important aspect.

\section{INTERACTIONS OF EXPLOSIVES WITH ELEMENTS WHICH ARE TO BE CUT}

In determining the requirements that explosive loads must meet in order to create breaches, first and foremost it is necessary to take into account the effects they have on personnel and the environment. The study aims to minimize damage to the environment by using small amounts of high-quality explosives.

In order to maximize the productive effects and minimize the harmful / noxious and non-productive ones, as well as other technological and cost conditions, there can be established the following requirements which have to be met by explosives and explosive mixtures used to make loads to create breaches in doors, in metal surfaces or for cutting support beams, anchor chains, metal shutters, etc.:

- to have a high shattering power and a high detonation speed;

- the explosion results in a large volume of explosive gases;

- to be sensitive to the detonation wave (to be initiated from a single detonating staple);

- to be plastic in order to be able to take the desired / necessary shape;

- to present safety in handling, transport and storage;

- to have a low manufacturing cost and to use local raw materials.

Given the above considerations and the purpose of the paper, these requirements may be met by oil and hexogen-type explosives (used in detonating wicks) and plastic explosive mixtures (actual charges and flexible cumulative charges).

The whole study was based only on experiments carried out with detonating wick and explosive plastic itself (C4, DEMEX or HITEX - the name of the Romanian variant), which is hydrophobic and flexible cumulative loads performed on land and then in the underwater environment. Most plastic explosive mixtures are over $85 \%$ hexogen based. 


\section{Technium Sustainability}

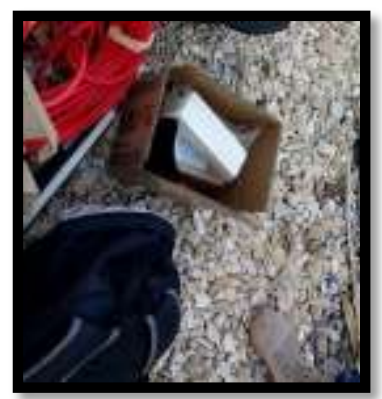

a)

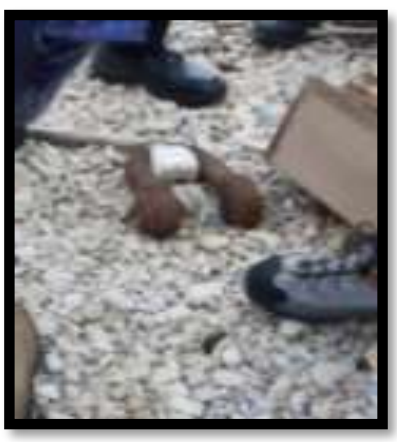

b)

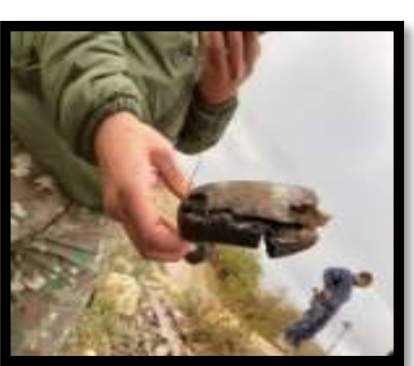

c)

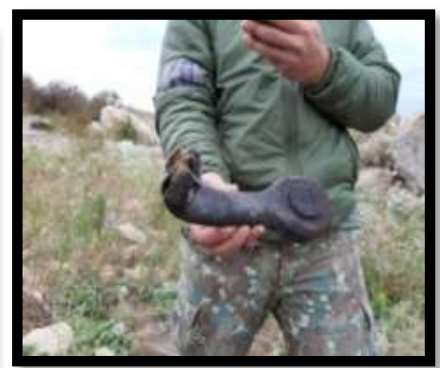

d)

Figure 1. Metal joining keys cutter with $\varnothing=40 \mathrm{~mm}$ (DES BLAST type) HITEX type plastic explosive cutting - a $250 \mathrm{~g}$ block was used for this test.

a) HITEX type plastic explosive - 500g block [11] and detonating wick with which the tests were performed b) joining / assembly key prepared for tests, c) test result performed under water, d) test result performed on the ground surface
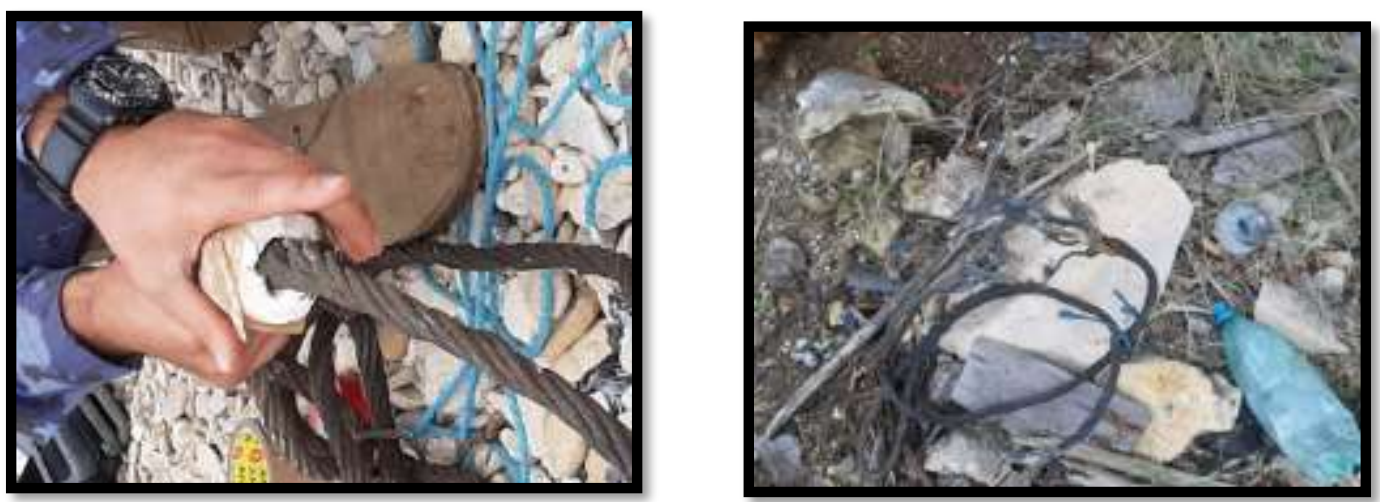

Figure 2. Experimental study of the possibilities of cutting a metal rope with HITEX type Romanian plastic explosive (a quantity of $150 \mathrm{~g}$ HITEX was used).

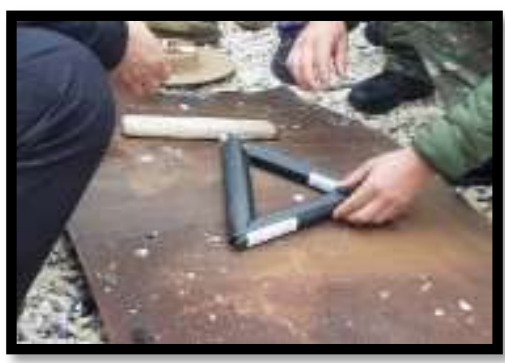

a)

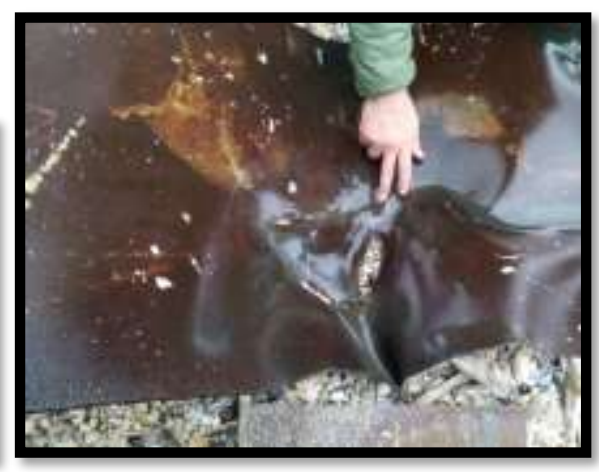

b)

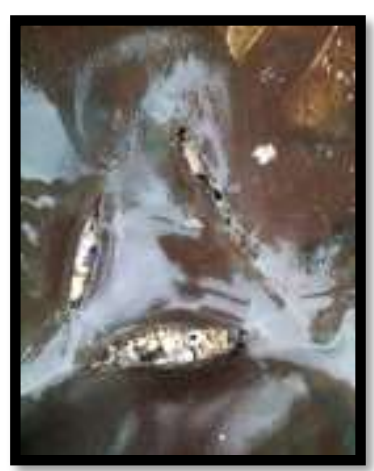

c)

Figure 3. Attempts to create breaches in metal doors were performed with flexible cutting: a) DES made of flexible cutting blades ICTRM 10 (made at UPS Dragomirești) with cumulative effect of BLADE type) and HITEX. Underwater cutting on the contour of a $10 \mathrm{~mm}$ thick naval sheet with cumulative effect type combined at the corners with explosive type HITEX (produced at UPSD), b) and c) the effect obtained 
Establishing the constructive variants of the explosive load is done depending on the mission and target.

In choosing the DES and the explosive, the following main factors will be taken into account: the type of mission, the deployment environment and the actual place for its location, the type of possible obstacle encountered, the weight (buoyancy) of the chosen devices and their reliability.

The detonation of the explosive load and the calculation of the energetic and detonation characteristics will be performed by the heads of the work team that ensures the surface.

The generation of shock waves in the environment of creating the breach and their targeting as well as the establishment of safety distances for the personnel participating in the mission are very important aspects on which their lives practically depend. The effect of the shock wave in the air differs a lot from its effect under water (water being an incompressible environment), the safety distance also differing a lot.

Due to the properties of air, considered a compressible gas mixture, after the detonation of an explosive substance, a discontinuity in the values of pressure, density and ambient temperature will occur.

The main effects of the explosion are: local destruction caused by the relaxation of reaction products, the effect by blowing due to the shock wave, the effect obtained by splinters, local fires, light and sound effects that induce panic and uncontrolled reactions.

The shock wave is an expansive wave, and its destructive effect is manifested in limits much greater than the destructive effect of explosives. A shock wave is fully characterized if three independent values are known: the initial shock intensity or its Mach number or particle velocity, the duration of the positive phase and the momentum (product force - time) on a unitary surface. Sometimes it is desirable to know the arrival time (the time required for the shock wave to travel the distance between the explosive load and the target).

The overpressure in front of the shock wave, $\Delta \mathrm{p}_{\mathrm{f}}$, for the explosion in the air, is calculated with the relation:

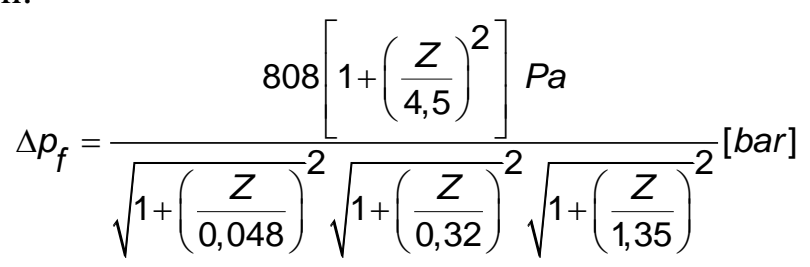

where:

$\mathrm{Pa}$ - air pressure at the time of detonation [bar];

$\mathrm{Z}$ - scaled distance $[\mathrm{m}]$.

$\mathrm{W}$ - the equivalent in kilograms of TNT of the explosive substance;

$\mathrm{R}$ - the distance in meters separating the place of disposal of the explosive and the target, the objective considered $[\mathrm{m}]$.

The scaled distance, $\mathrm{Z}$, is a theoretical quantity that matches the amount and type of explosive detonating, the atmospheric conditions at that time on one hand, the standard load and atmosphere on the other hand in order to obtain the same effect at equal spaces with the cube of explosive distance - target. It is established as follows:

$$
Z=f_{d} \cdot \frac{R}{W^{1 / 3}}[m]
$$

in which:

fd - distance factor;

$\mathrm{R}$ - the space separating the load objective [m];

$\mathrm{W}$ - the TNT equivalent of the amount of explosive used $[\mathrm{Kg}]$. 
In the future we will perform measurements using underwater pressure sensors to assess the overpressure in front of the shock wave generated by the detonation of an explosive load, hoping that these measurements will establish safety distances and assess the effects on various targets in the vicinity of operates with explosive loads in order to create breaches.

To assess the effects of the detonation on the different objectives (considered targets) in which a breach is to be achieved, Table 1 can be used.

The hereby application was made for explosive loads, with different masses, according to the values calculated for the explosive devices presented in the previous chapter, variant I and II (see fig. 4.8). The choice of the safety distance is made according to the existing objectives in the area where the application for creating the breaches is made, as well as according to the degree of risk accepted in the ordered mission. In order to choose the acceptable critical values of the overpressure in front of the shock wave, see table 1.

The estimation of the effect is done by framing and comparing the value of the overpressure in the front of the shock wave $\Delta \mathrm{p}_{\mathrm{f}}$ with its values, which produce certain effects, as it can be seen in the following table:

Table 1. The overpressure values $\Delta \mathrm{p}_{\mathrm{f}}$ from the front of the shock wave and the different damages produced [15]

\begin{tabular}{|l|c|}
\hline \multicolumn{1}{|c|}{ TYPES OF DESTRUCTION } & $\Delta \mathrm{p}_{\mathrm{f}}[\mathrm{mbar}]$ \\
\hline Minimal damage to windows & $1-3$ \\
Breaking of ordinary windows & $10-15$ \\
Minimum overpressure that causes damage to guided missiles & $15-25$ \\
Tearing windows, falling plaster, insignificant damage to some buildings & $35-75$ \\
People knocked to the ground & $70-100$ \\
Deformation of metal plates & $75-125$ \\
Damage to the wooden or BCA walls of ordinary houses & $75-150$ \\
Damage to walls made of concrete elements & $200-300$ \\
Deformation of tanks for petroleum products & $200-300$ \\
Demolition of telegraph poles and high voltage & $300-500$ \\
Significant damage to buildings with mechanical resistance & $300-500$ \\
Breaking the eardrums & $350-1000$ \\
Partial destruction of resistance structures made of reinforced concrete & $400-600$ \\
Overturning of means of transport & $700-800$ \\
100\% lethality & 6000 \\
Almost complete destruction of most buildings & $2000-5000$ \\
Formation of craters in medium-resistancesoils & $20000-30000$ \\
\hline
\end{tabular}

\section{DES TYPES FOR THE USE OF COMBAT DIVERS}

Given the constructive solutions of explosive devices and ammunition briefly presented above and in Figure 4, but also taking into account the experience in the use of explosives and explosive devices, this chapter will present the chosen constructive variants. As it is known, the principle of destroying obstacles is based on the target generation of shock waves.

Because the shock can be induced:

either as a high-velocity impact between a projectile (explosive propulsion) and a target;

$>$ either as a result of the detonation of explosives in contact with the obstacle / target (taking place the transmission of the shock wave in the target), 


\section{Technium Sustainability}

$>$ the constructive variants must take into account the particularities of the systems that can achieve these two modes of operation.

In the first situation, the impact requires an initial distance, called the stand-off in AngloSaxon literature, between the explosive load and the obstacle. Constructive solutions that enhance this effect are mainly used for ammunition, fired from a launcher / weapon and less for manually placed explosive devices.

For reasons of constructive and functional simplicity, the hereby study will address the second way of generating shock waves, namely the detonation of explosives in direct contact with or in close proximity to the obstacle.

From the point of view of the overall dimensions of the device, it must not be forgotten that it is required to create breaches of certain dimensions, hereinafter referred to as Lxl. This presupposes an at least parametric approach, i.e., the evaluations will be performed in literary form, and in the end calculation applications will be performed for certain values of the parameters Llength and l-width. It is no less true that there is a possibility that L corresponds to 1, i.e., a squareshaped breach is obtained.

There are two ways to arrange the explosive load so as to obtain a rectangular breach. These are graphically represented in the following figure.

Table 2. Amount of explosive ( $\mathrm{g}$ ) for variant I $\left(\rho=1,5 \mathrm{~g} / \mathrm{cm}^{3}\right)$

\begin{tabular}{|c|c|c|c|}
\hline & \multicolumn{2}{|c|}{$\mathrm{L}=\mathrm{l}(\mathrm{m})$} \\
\hline & & 0,60 & 0,80 \\
\hline \multirow{4}{*}{$\begin{array}{c}\mathrm{D} \\
(\mathrm{mm})\end{array}$} & 10,00 & 141,37 & 188,49 \\
\hline & 20,00 & 565,48 & 753,98 \\
\hline & 30,00 & 1272,34 & 1696,45 \\
\hline & 40,00 & 2261,94 & 3015,92 \\
\hline
\end{tabular}

Table 3. Amount of explosive ( $\mathrm{g}$ ) for variant I $\left(\rho=1,6 \mathrm{~g} / \mathrm{cm}^{3}\right)$

\begin{tabular}{|c|c|c|c|}
\hline & \multicolumn{2}{|c|}{$\mathrm{L}=\mathrm{l}(\mathrm{m})$} \\
\hline & & 0,60 & 0,80 \\
\hline \multirow{4}{*}{$\begin{array}{c}\mathrm{D} \\
(\mathrm{mm})\end{array}$} & 10,00 & 150,80 & 201,06 \\
\hline & 20,00 & 603,18 & 804,25 \\
\hline & 30,00 & 1357,16 & 1809,55 \\
\hline & 40,00 & 2412,74 & 3216,98 \\
\hline
\end{tabular}

\section{About the composition of the explosive breach device, we can state that:}

The explosive load assembly consists of the explosive load (2), which is inserted into the housing (casing), marked on the drawing with (3). The detonator (4) has the role of initiating the detonation of the explosive and it is mounted in the opening made in the explosive load or in the additional detonator (for variant II).

The explosive load with its coating can be introduced into a confinement membrane (5), filled with the confinement medium (6) consisting of water or water-based mixtures. The explosive load assembly with the containment diaphragm is attached to the bracket. 


\section{Technium Sustainability}

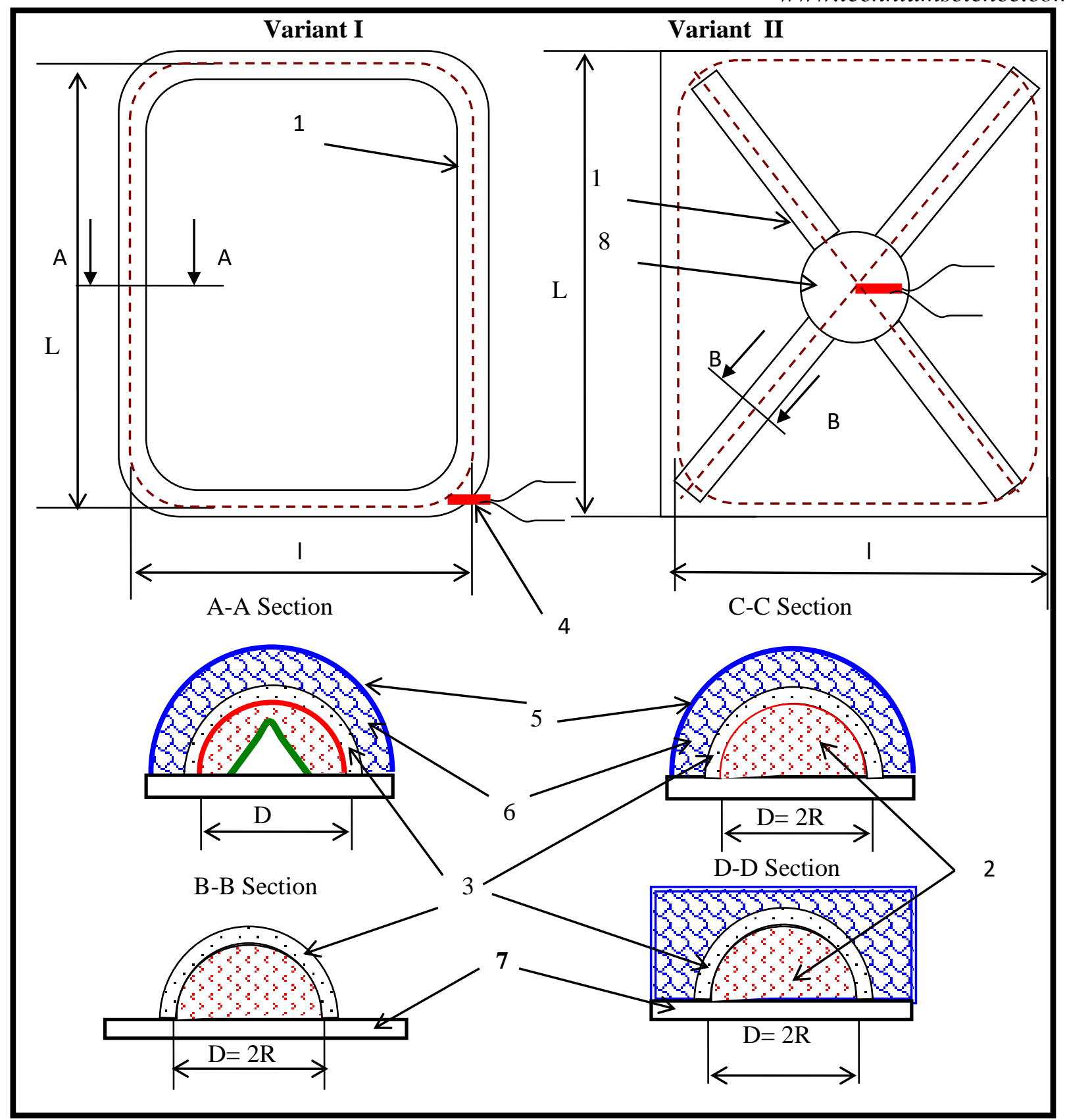

1- Explosive load assembly;

2- Explosive load

3- Housing (Jacket)

Figure 4. Compositio
5- Confinement membrane

6- Confinement environment

7- Explosive load support plate 7

ition (special explosive devices) DES for creating breaches
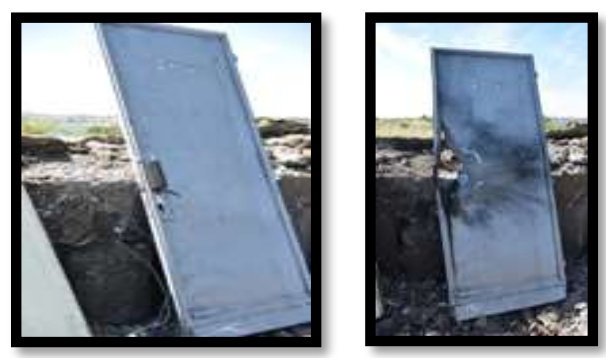

Figure 5. Cutting with DES flexible creating BLADE type breaches, made of DEMEX type plastic explosive $(1150 \mathrm{~g} / \mathrm{ml}$ with a length of $140 \mathrm{~mm})$ fixed on the lamella from a sintered copper mixture, fixed on a metal door handle. 


\section{Technium Sustainability}

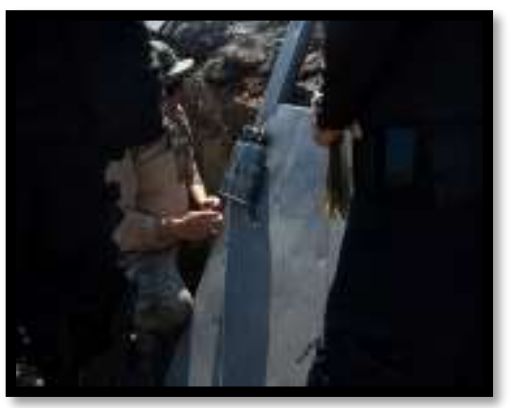

a)

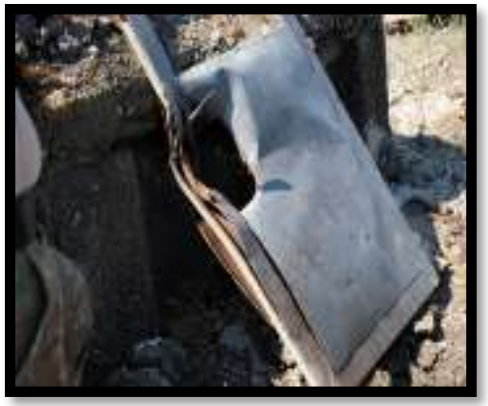

b)

Figure 6. a) Experiments performed on metal doors and b) the effects obtained.

Materials used: FD fixed on $31 / 21$ bottles filled with water, the fixing on the door surface was made with "Breachers Tape" type double adhesive tape, NONEL type staple was used.

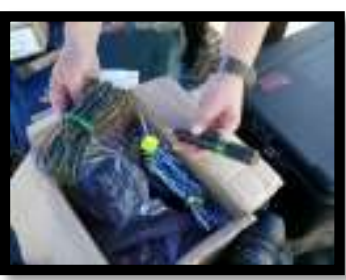

a)

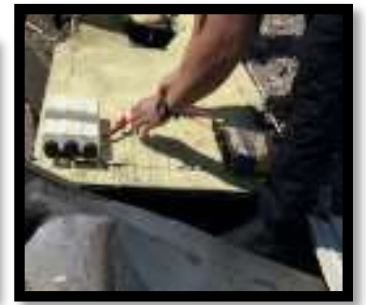

b)

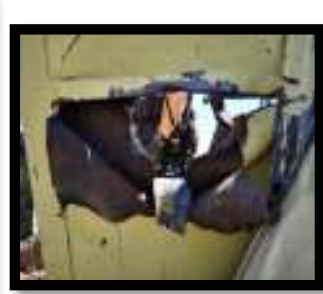

c)

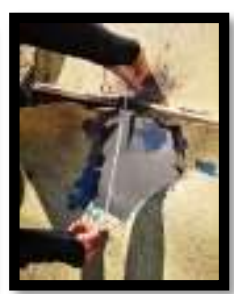

d)

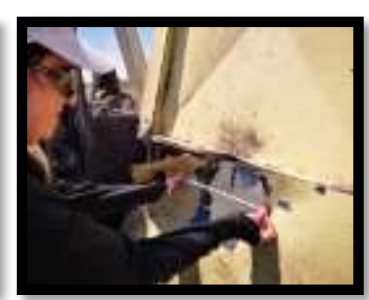

e)

Figure 7. DES consisting of 3 bottles fig. b) - with square cross section - capacity of 500ml and/or $250 \mathrm{ml}$ - filled with water, on which an explosive FD snail of $20 \mathrm{~g} / \mathrm{ml}$ was applied, with a length of: $\mathrm{L}=1.5 \mathrm{~m}$ double adhesive tape "Breacher Tape", initiated with NONEL staples fig. a), measuring the gap in the metal door Fig. c), d), e).
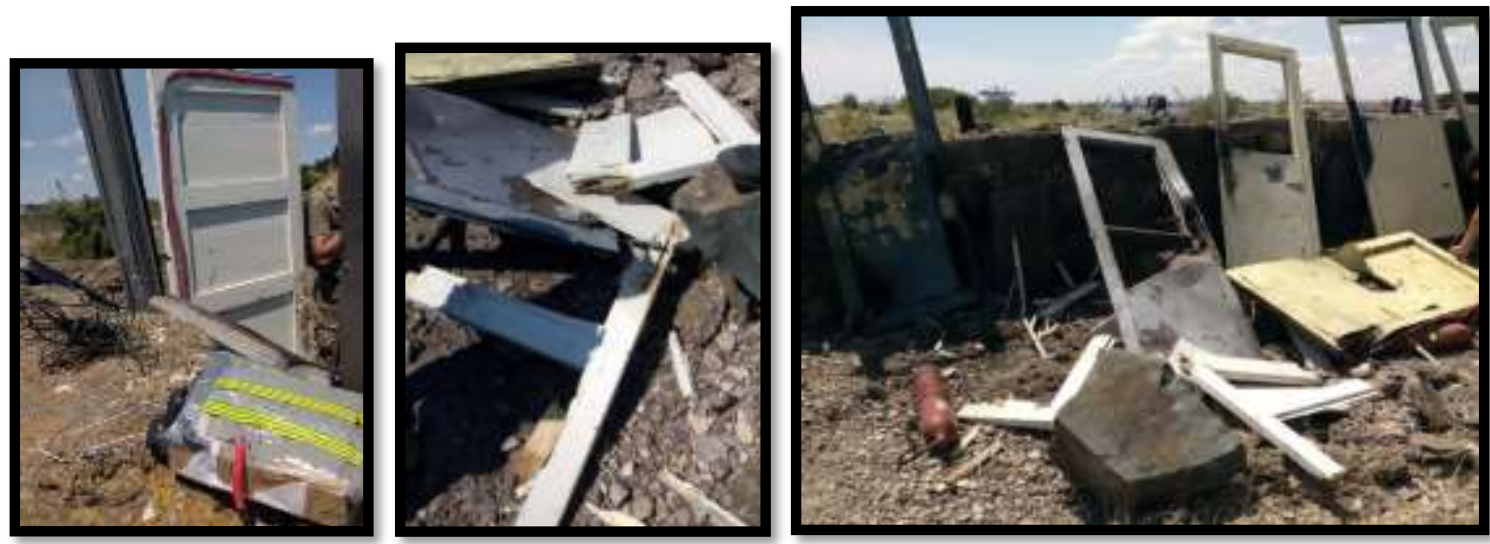

Figure 8. DES applied at various points on wooden and metal doors of different types;

DES consisting of FD attached on rubber of thickness $h=15 \mathrm{~mm} \mathrm{l}=50 \mathrm{~mm}$ and $\mathrm{L}=200 \mathrm{~mm}$, placed on handles and hinges of metal doors; 


\section{Technium Sustainability}
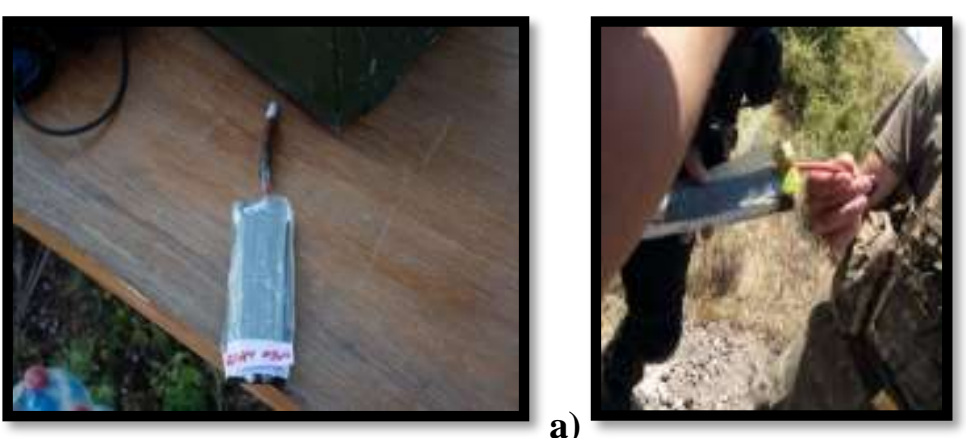

www.techniumscience.com

a)

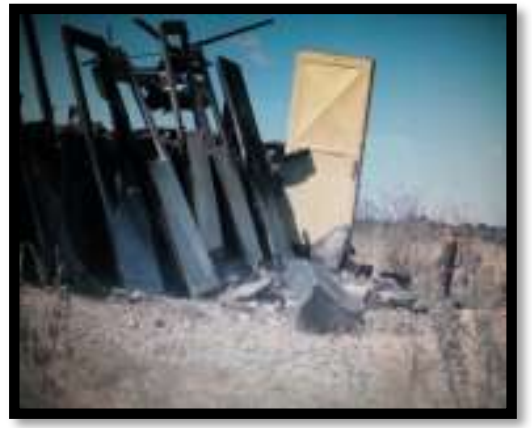

d)

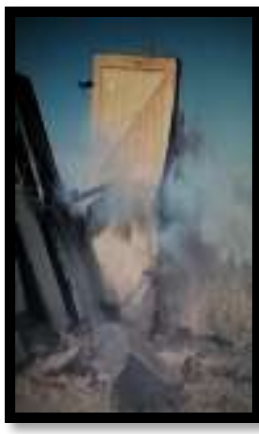

e)

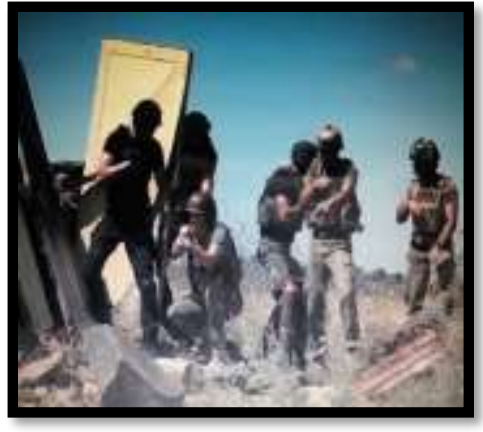

f)

Figure 9. Experiments performed with special explosive devices (DES consisting of FD attached on rubber of thickness $\mathrm{h}=15 \mathrm{~mm} \mathrm{l}=50 \mathrm{~mm}$ and $\mathrm{L}=200 \mathrm{~mm} \mathrm{a,} \mathrm{b,} \mathrm{c} \mathrm{and} \mathrm{d)} \mathrm{performed} \mathrm{by} \mathrm{SSLI} \mathrm{-} \mathrm{combat}$ divers and, the effects obtained with their help (see photo e and f).

Photo c) represent the DES consisting of FD strip load mounted on rigid rubber with a thickness of $25 \mathrm{~mm}$ (high density polyethylene, cardboard or wood could be used), "strip" type effect (FD fixed on solid rubber)

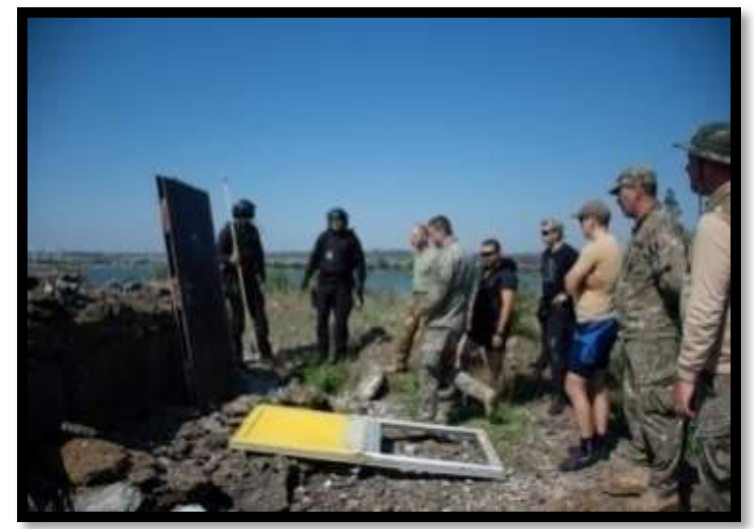

a)

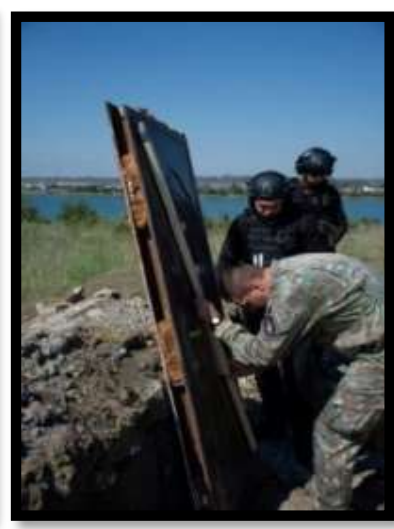

b)

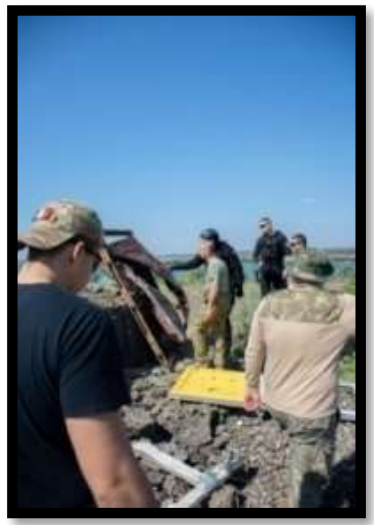

c)

Figure 10. a) Experiments performed on exterior doors, b) fixing STRIP type load (FD fixed on wooden edged board: Length $=2 \mathrm{~m}$, width $=50 \mathrm{~mm}$, height $=25 \mathrm{~mm}$ ) and, c) the effects obtained.

Materials used: a row of FD of $20 \mathrm{~g} / \mathrm{ml}$ fixed in the edge of a wooden bar with $\mathrm{L}=2 \mathrm{~m}$, $\mathrm{w}=0.07 \mathrm{~m}, \mathrm{~h}=0.02 \mathrm{~m}$. The fixation on the door surface was made with double adhesive tape, "Breachers Tape", the detonation was done with NONEL staple.

In conclusion, all DES types considered necessary for the missions of the groups of divers were carried out, which were applied on the targets brought and installed high on the dune of the 
"SCF 0" polygon or underwater; in general there were mounted detonic electrical staples (CEDs) or NONEL staples with reophors having a length of $\mathrm{L}=10 \mathrm{~m}$ and with the firing system by pushing (syringe type) and pulling; experiments were performed for all necessary and desired DES, at that time, by this type of operationalized groups of divers. For divers of SISMA groups, CEDs were used (see figs. 1, 2 and 3) with and without delay.

\section{CONCLUSIONS AND DEVELOPMENT DIRECTIONS FOR THE FUTURE}

The hereby paper, far from being a complete approach to the topic required by deep-sea and foray divers, seeks to present the extensive study of the issue addressed by the CPSA Diving Center Laboratory - respectively devices and work equipment specific to the activities of professional divers.

Testing a multitude of explosive devices especially designed for different groups of divers in order to cut and drill light obstacles in the underwater environment is a national premiere, while ensuring the solution of problems that have arisen over time.

On this occasion, it was found that there are very large differences between the effect obtained with similar devices in the terrestrial environment compared to the effect obtained in immersion. Most of the time a quantity of explosive that on land led to the desired effect, under water only deformed the same metal structure; in order to cut a certain structure, one had to use explosive in much larger quantity, a problem which must be solved in the future. The solution that proved to be safe in most cases was the use of BLADE flexible cutting blades.

Given that water is an incompressible environment and that so far there has been nationally no question of studying and finding the values of the pressures developed by shock waves caused by underwater explosions produced by the newest and most explosive performance of the moment, the $\mathrm{CD}$ team made up of engineers, teachers, divers, pyrotechnicians, breachers and engineers is interested in the phenomena that occur underwater depending on the nature and force of the explosion, the depth at which it occurs, distance, etc. We believe that further research in this area should focus on: the pressures developed by the shock wave front caused by the explosion underwater of certain quantities of explosives placed at different depths and in different places; it is proposed to perform experiments in hyperbaric environment and then theoretical / applied studies on these topics should be carried out. The measurements required by the experiments will be performed with the new sensors for measuring the pressure of the shock wave formed as a result of submarine explosions, which together with the related software have already been purchased this year.

Another topic of interest for deep-sea divers is, as we have previously pointed out, the demolition of calcareous structures and the demolition of large underwater stabits, subjects that can be studied in the future.

Consequently, this $\mathrm{CD}$ project has managed to bring together institutions and people with extensive experience, accumulated over time, in different directions specific to their branch but also related to their field of study, respectively on the topic proposed by the diving departments of the Center Diving. The topics proposed and dissected in the practical meetings of the project, strictly developed on the issue of interest of divers, proved to be of great interest for specialists from different cities of the country, the experience gained over time being disseminated and enriched both theoretically and practically between elite units of the National Defense System from Constanța, Bucharest, Brăila and Tulcea reunited within the present CD project. 


\section{Acknowledgment}

I would like to thank Colonel (r) Engineer Marius MOLDOVAN, $\mathrm{PhD}$ and Colonel Engineer Marin LUPOAIE, PhD (Vice-Rector of ATMB) -entitled personalities in this field for making breaches in light obstacles and demolition of various types of structures - without whose collaboration the present research-development work could not have reached this level. I would also like to thank Colonel (r) Engineer Florea CRISTESCU, a senior engineer, with whom the LCPSA of the Diving Center collaborated between 1997 and 2005 on issues related to DEI / DES.

\section{SPECIALTY TERMS}

Booster $=$ element that contains a high-explosive sensitive enough to be initiated by small amounts of explosive in the composition of the warhead or staple and strong enough to detonate the basic explosive charge. [14, p. 53]

Critical detonation diameter is the smallest diameter from which the explosive charge is likely to detonate outdoors.

Specialized Improvised Device (SID) is an improvised explosive device designed to destroy, disfigure, distract, or harass, which incorporates explosive substances and / or toxic and biological chemicals or radioactive materials. This category includes all types of explosive devices, including improvised explosive devices / IEDs initiated by sophisticated systems, controlled by radio, infrared, photoelectric, etc. [14, p. 54]

Anti-lift device $=$ device designed to detonate ammunition to which another ammunition or nearby explosive charge is attached, if intervened. [14, p. 54]

Explosive equivalent $=$ the equivalent power of an explosive compared to an equal amount of TNT. Usually, the equivalent power is higher or lower than the power of the trotyl and is expressed in values to two decimal places. For example: C-4 plastic explosive is 1.37 times stronger than TNT. [14, p. 54]

HYDROPHOBIC $=($ Chem. $)$ which does not combine with water in any form, which does not soak with water. (Med. On humans and animals) Which, due to a pathological condition, cannot withstand the sight of water.

Squib $=$ explosive $=a$ "squib" can be a miniature explosive device used in a wide range of industries, from special effects to military applications - it can look like a firecracker.

Risk $=$ the possibility of an accident occurrence, expressed in terms of the severity and probability of the hazard occurrence.

\section{LIST OF ABBREVIATIONS AND ACRONYMS}

AISRAS = Section for Authorization, Inspection, Standardization and Regulation of Diving Activities;

ATMB = Military Technical Academy Bucharest

CPSA = Underwater Research Center of the Diving Center;

$\mathbf{C D}=$ research - development;

CED = detonating electrical staples;

CT = counterterrorism; 
DEF $=$ fixed explosive device with length (height) of $\sim 0.8 \div 1 \mathrm{~m}$ and width of $\sim 0.6 \div 0.8 \mathrm{~m}-$ creates a breach in the wall for the dimensions of a soldier with combat equipment;

DEI = improvised explosive device;

DES = special explosive device;

DGPCT $=$ General Directorate for Preventing and Combating Terrorism;

EO $=$ Explosive Ordnance $=$ explosive ammunition;

EOD $=$ Explosive Ordnance Disposal = demining or removing explosive devices;

FD = detonating wick;

FPAS Course $=$ Diving Training, Preparation and Training Course

HMX = octogen;

IED = Improvised Explosive Device (DEI);

$\hat{\mathbf{I E x}}=$ explosive load,

$\mathbf{L C D}=$ research-development work;

LCPSA = Underwater Research Laboratory of the Diving Center;

PENT = Pentaerythritol tetranitrate;

RDX = hexogen;

SISMA = Deep Diving Intervention Squad;

SSLI = Incursion Combat Diving Section;

SSP = Special Pyrotechnic Service;

SSP-DGPCT $=$ Bomb Squard within Antiterrorist Brigade $=$ Special Pyrotechnic Service of the General Directorate for Preventing and Combating Terrorism

TNT $=$ trotyl cast, pressed, etc.;

UPS Dragomirești = Special Products Plant Dragomirești;

UXO = Unexploded Explosive Ordnance $=$ unexploded ordnance;

\section{REFERENCES}

[1] Știința și tehnica folosirii explozivilor în industrie (The science and technique of using explosives in industry), author: Dumitru FODOR, Editura AGIR 2016;

[2] Breaching in light obstacles, Urbanism. Arhitectura. Constructii - Revista INCD URBANINCERC vol. 6/2015 ISSN 2069-0509, 2015, authors: MOLDOVAN M., LUPOAE M., BACIU C., CONSTANTIN D.,

[3] Aspects regarding developing of a breaching charge, author: Marius MOLDOVAN, International Conference "Greener and Safer Energetic and Ballistic Systems", Academia Tehnică Militară, 2015.

[4] The influence of water layer in case of explosive breaching devices, authors: MOLDOVAN M., ENACHE C., Military Technical Academy Review, Vol.XXV, No.3, 2015.

[5] Aspects regarding the Water Jet Propulsion using Explosive Energy for Door Breaching, authors: LUPOAE M., GOGA D.A., CONSTANTIN D., BACIU C., MOLDOVAN M., Proceedings of the World Congress on Engineering 2011, London, Vol III, No.2, 2138-2142, 2011.

[6] Wikipedia the free encyclopedia, http://www.wikipedia.org;

[7] Hallodictionary online;

[8] Dex online dictionary.Accessed on 26.10.2020 ora 11.11, r pg18 etc.;

[9] Ventilation systems for special ships, authors: VOLINTIRU O. N., PRUIU A., SCURTU I.-C., Buletinul Agir, 2017, ISSN-L 1224-7928, BDI: Index Copernicus International, Academic Keys, get CITED, ISSN Online: 2247-3548;

[10] Modelling and optimization of HVAC system for special ships, author: O. N. Volintiru, RESORT Conference 2018, Resort-International Conference on Sustainable Future and Technology Development, Volume 1122, 15 October 2018, Bucharest, Romania; 


\section{Technium Sustainability}

[11] Site-ul Uzinei de Produse Speciale Dragomirești, Încărcături explosive pentru uz civil prod. de UPS / Special Products Plant Dragomirești website, Explosive loads for civilian use prod. of UPS $\sim$ Home - Desprenoi/ About us - Produse/ Products - Contact $\sim$, accesat în/ accessed in 2018- (C) 2010 by UPS Dragomiresti | Made by Etajuldoi.ro - Webdesi;

[12] Strategia națională de prevenire și combatere a terorismului - aprobată în ședința CSAT din 05.04.2002/ The National Strategy for the Prevention and Countering ofTerrorism - approved at the CSAT meeting of 05.04.2002;

[13] EOD - 1 Instrucțiuni privind sprijinul EOD în armata României / Instructions on EOD support in the Romanian Army, MApN, SMG, Buc. 2006;

[14] (FM9) EOD - 2 Instrucţiuni privind măsurile de siguranţă pe timpul intervenţiei pentru neutralizarea şi distrugerea muniţiilor şi dispozitivelor explozive/Safety instructions during the intervention of neutralization and destruction ammunition and explosive devices - MApN, SMG Buc., 2006;

[15] Explosive Shocks in Air, originally, author: Gilbert Ford Kinney, published by The Macmillan Company, New York, 1962 and Explosive Shocks in Air, Second Edition, pg.189\&260, authors: Gilbert Ford Kinney \& Kenneth Judson Graham, originally published by Springer - Verlag Berlin Heidelberg New York Tokyo in 1985. https://www.amazon.com/Explosive-Shocks-Air-Gilbert$\underline{\text { Kinney/dp/3642866840?asin=3642866840\&revisionId=\&format=4\&depth }=1}$ 